\title{
Film's Illusions
}

\author{
By Jan Uhde
}

Fall 1995 Issue of KINEMA

\section{FILM'S ILLUSIONS: KULESHOV REVISITED}

FOR a century, moving images have been captivating millions around the world. Yet many of the attractions which bring people into cinema theatres and, more recently, which fix their eyes to television screens for hours on end, are only illusions. We say "movies" but no movement exists in film -- it is produced in the spectator's mind. The mechanics of this illusion is explained today with reference to two optical phenomena: The persistence of vision, described theoretically by Peter Mark Roget in 1824, and the so-called phi-phenomenon, also known as "stroboscopic effect," discovered by the gestalt psychologist Max Wertheimer. ${ }^{(1)}$

These two effects permit the human brain to perceive a series of related static images (more precisely, motion phases) as a continuous motion. It is this illusion that permits the existence of moving pictures and, more recently, television. Unlike the motion pictures, which need only the illusion of motion, the electronic images of television and video create both the illusion of motion and image. These illusions are the sine qua non prerequisite of the audiovisual media. Without them, they would not exist. Yet they are not the only illusions which the film and television media produce.

There is also the illusion of depth (or the third dimension). ${ }^{(2)}$ Both the celluloid film and the electronic image are by definition two-dimensional; they are projected and observed on a two-dimensional surface. Despite this, film (and television) audiences have the perception of depth -- or rather illusion of depth. The intensity of this illusion varies according to the technology and technique applied by the filmmaker. Since the early years of motion pictures, filmmakers have been aware of this phenomenon which they control through a variety of techniques. For example, the introduction on a massive scale of the long take technique (also called synthetic editing) through Orson Welles' Citizen Kane $e^{(3)}$ brought about an increased illusion of depth. This technique has become one of the fundamental stylistic characteristics of the post-World-War-II cinema world-wide. $^{(4)}$

The illusion of motion and depth in motion pictures, (including the illusion of image in tele-media) are fundamental factors in film and television's intrinsic disposition to produce in the viewer an intense illusion of the real world. The affinity between the projected image and the surface reality creates a strong persuasive pressure on the audience who easily accepts the film image as the image of reality. ${ }^{(5)}$ This effect has been defined by the German film historian and theoretician Siegfried Kracauer: "Struck by the reality character of the [resultant] images, the spectator cannot help reacting to them as he would to the material aspects of nature in the raw which these photographic images reproduce." ${ }^{(6)}$ Paradoxically, this "reality character" of the film image may have little to do with the truth.

There are further reasons why the film audience tends to submit easily to the power of the cinematic illusion; one of them is the very nature of film viewing. In the cinema a person watches the screen in relative isolation -- cut off from the outside world by the darkness of the auditorium and seating arrangement. This creates a distinctive atmosphere which the German psychologist Hugo Mauerhofer calls the "cinema situation."(7) The "cinema situation" intensifies the hypnotic power of the film image.

The intensity of the film-viewing experience can be illustrated by the fact that screen images may produce strong physiological reactions by the viewer, including increase of heartbeat rate, nausea, and vertigo. It is common knowledge that already during the first public film projection by the brothers Lumière in 1895, some front-row viewers panicked at the sight of the approaching locomotive in the Arrival of the Train. Extreme audience reactions (nausea) have been reported in connection with some horror films such as William Friedkin's The Exorcist (1973). Nausea and vertigo have also been reported by audiences viewing images of vigorous motion (via aircraft, boat, rollercoaster, etc.), particularly those produced by large-screen and experimental projection systems such as Omnimax and Circorama; most of these systems stress the illusion of three-dimensionality. The extreme psychological effects of projected images provided the inspiration for the 
writer Anthony Burgess and director Stanley Kubrick who portrayed them through the "Ludovico Treatment" in their 1971 film Clockwork Orange.

Illusion of reality leads to viewers' identification with the events on the screen. According to Metz, "... the spectator can do no other than identify with the camera..."(8) Jean-Louis Baudry speaks of "two levels of identification." ${ }^{(9)}$ It should be stressed here that the capability to produce this illusion and identification is not exclusive to the film medium. It can be detected in other art forms, including the performance arts and literature. In the area of popular music, for example, these factors can become very powerful at times.

In motion pictures, the level of audience identification with the story reaches a considerably greater degree of intensity when compared to similar effects observed in most art forms, such as stage drama and literature. The German theoretician Walter Dadek speaks of an "unprecedented increase of the illusion of reality" [trans. J.U.] of the film image. ${ }^{(10)}$ Also, the emotional involvement of the film viewer is deeper than that of the television (and video) spectator: the relatively small size of the picture tube, the lower image definition and colour quality reduce the illusion. Moreover, the private mode of viewing which is open to a variety of disturbances and the viewer's freedom to change channels or to engage in other activities, weaken the identification process.

Conventional movies have traditionally concentrated on the audiences' emotions. Soon after the film begins, the spectator becomes virtually a "part of the story;" this process has been most eloquently illustrated in Woody Allen's 1985 film Purple Rose of Cairo. Indeed, emotions play a pivotal communicative role between the film and audience. However this approach has significant drawbacks. An essentially emotional address reduces or suppresses the viewer's critical, more intellectual faculties which would promote a more objective analysis of the film. The viewer, having identified with his or her character, also assumes this character's point of view. The result is a one-sided interpretation of the conflict presented by the film's narrative; other equally relevant points of view are neglected. This trance-like state into which the audience plunges during filmviewing promotes passive consumption.

Since Griffith's times, the illusion of reality has become one of the basic elements of the conventional (Hollywood) story-telling. Emotional address promotes the viewer's identification with the film's characters; this has helped to create the Hollywood Star System, still quite powerful after several decades of heavy use, including intermittent attempts to reduce it. Identification mechanisms have been routinely exploited in propaganda film, including newsreels, war films and TV commercials. ${ }^{(11)}$

The questions of illusion and identification process in film have been repeatedly pointed to by filmmakers and critics; especially since the 1960s some directors, including Jean-Luc Godard, Rainer Werner Fassbinder and more recently, Quentin Tarantino, have been trying to reduce the illusion aspect of film by introducing Brechtian distancing effects (actors' stepping out of the role, interruptions, and other artifice) to achieve better equilibrium between film's emotional and intellectual components. ${ }^{(12)}$ Illusion and distancing are one of the dialectical counterparts involving the film and television medium. ${ }^{(13)}$

The capacity of film to produce the illusion of reality is directly related to the medium's technological advancement. Technological innovation has always been striving towards "improvement" -- meaning increasing the naturalistic element of the film medium. It has been usually promoted by the production industry. These advances concern the image quality, colour and sound reproduction (stereophony and stereoscopy). A variety of established and experimental systems can be cited, including Cinemascope, Circorama, Sensurround, Surroundsound, 3-D, Omnimax and, most recently, the "virtual reality."

Parallel with this development, efforts have been made by directors and other artists aimed at disrupting the simplistic xeroxing of reality. Artists' attempts at controlling film's technological factor have been evident since the avant-garde movement of the 1920s and 1930s and have continued until this day. More recent examples of tendencies to disrupt the film medium's affinity towards versimilitude include Federico Fellini's legendary "sea" made in the studio out of plastic sheets (And the Ship Sails On, 1984), Yasujiro Ozu's and Michelangelo Antonioni's use of off-screen space, the minimalist style of Jim Jarmusch, and the expressive use of sound by Taviani brothers.

One of the most significant theoretical discoveries in the history of film is the effect discovered by Lev Kuleshov in the early 1920s in the Soviet Union. Kuleshov proved that two shots projected in succession are 
not interpreted separately by the viewer; in the audience's mind, they are integrated into a whole according to the well-known equation $\mathrm{A}+\mathrm{B}=\mathrm{C}$ (in which $\mathrm{A}$ and $\mathrm{B}$ are the two joined shots and $\mathrm{C}$ is a new value, not originally included in any of these shots).

This effect is extremely powerful. A scene, for example, consisting of the shot of aircraft dropping bombs followed by the shot of a burning village will be routinely interpreted as "these aircraft have bombed this village." Needless to say that these two shots could have been filmed at different places, at different times, and the burning village may have been the result of an accident. French historian Marc Ferro's comment on Kuleshov's discovery goes further: "Ainsi une image est toujours commentée, doublée, suivie ou précédée d'une autre image. Et là commence, avec ou sans montage, la manipulation." (14)

The Kuleshov effect has been adequately described, analysed and explained. Yet its implications have been generally seen in a restricted context. Actually, the Kuleshov principle is analogous to the above-mentioned mechanisms which produce the illusion of film motion. On both occasions, the viewer perceives individual and separate elements and organises them into a larger context by adding the causal relationship between them. This relationship exists only in the viewer's mind. A series of still images, when projected, results in the illusion of motion itself. A series of larger units (shots), when shown in sequence, will result in an illusionary narrative meaning.

The effect discovered by Kuleshov and its practical use by filmmakers in the editing process pertain mainly to the contextual relationships within the structure of the film (or other audio-visual) work as a whole. Also, most theoretical discussion of the Kuleshov effect and its implications have been conducted from this point of view.

Such an approach is understandable. In the time of Kuleshov's discovery, film-viewing was a different experience from what it is today. Among other things, the presentation of motion pictures was conducted in an environment separated from other activities. To "go to the movies" normally meant to watch one feature (in some cases two, or a feature with a newsreel or a short). The film performance was clearly demarcated, had a formal beginning and an end (arrival to the film theatre, opening of the curtain, closing of the curtain, leaving the theatre, etc.). The audience saw the film in its own inner context, as a hermetic unit.

An important change in the film exhibition practice has been brought about by the introduction of television. As a result, motion pictures are now often seen to be a part of a larger unit -- the television programming; consequently, the nature of filmviewing as a discrete experience has been gradually lost. Watching film on television has become merely the watching of one program element, the whole consisting of newscasts, sitcoms, dramas, soap operas, detective stories, etc.

This has become particularly evident in commercial television which stresses seamlessness of programming. Commercial television does not know the formal intervals between individual program units or their segments. Economical considerations -- the dollar value of every second of broadcast time -- can be cited as the main reason of this practice. Similar concerns invented the strategy of continuously bombarding the telespectators with new impulses, to keep them glued to the picture tube thus keeping the audience ratings up. James Monaco calls this technique of seamlessness "seque," a term borrowed from musical vocabulary; seque had been used in this sense by American commercial radio stations. ${ }^{(15)}$ Through seque, the coherence of individual building blocks of television programming is further reduced.

Another important element reducing the autonomy of television program components are commercials ${ }^{(16)}$. As it is well known, commercials not only fill the space between the programming units (news, sportscasts, feature films, shows, etc.) but most importantly, they are inserted directly into these components. The very structure of the presentation unit is fractured, split into fragments of variable size, often less than ten minutes in length.

Thus the techniques of seque and the introduction of commercials between and into the program components significantly reduce the traditional autonomy of television programming units, including films, thus weakening their cohesion as separate programming elements. The audience's perception of individual films as individual works has become increasingly obscure. Sometimes, it may even be difficult to distinguish between the actual program and the commercial. 
The fragmenting of the programming elements' structure does not end here; one of the more recent practices is the insertion of commercial messages directly into the image. This routine which seems to be on the rise has not been as yet associated with televised feature films; it frequently appears in informative broadcasts, such as in weather forecasting. For example, a report on ultra-violet ray levels may be accompanied with images and logos of a sunglasses company; the forecast of a rainy day is accompanied with trade marks of an umbrella manufacturer, etc.

Considering the seamless character of television programming, it is not surprising to find that the mechanics of the Kuleshov effect applies even here, far beyond its common interpretation territory within the individual film work. In fact, Kuleshov's original experiment involved an isolated shot of the actor Ivan Mozhukin (Mosjoukine) juxtaposed with shots of other isolated images; Kuleshov commented on results of these juxtapositions without including them into a complete film work, or an explicit narrative sequence.

Generally, the Kuleshov effect has been used to explain results of a specific creative intention. This is how it usually occurs within a hermetic work of art. Yet this effect may also occur accidentally without any premeditation, and between nominally independent units of a television program (accidental context, the idea of which was exploited by the Dadaists). It has been documented more then once that the juxtaposition of separated and independent audiovisual structures within the larger structure of television programming will create new meanings; these may be intentional or they may emerge without any preconceived plan.

A well-known event which came into the focus and scrutiny of the media some years ago may serve as an effective example: An American television station customarily interrupted the broadcast of the popular serial Holocaust (Marvin J. Chomsky, 1978), dealing with the World War II genocide of Jews, with a commercial about a kitchen oven cleaner. Thus, just when the viewer was watching horrific images of the Nazi crematoria, he was suddenly presented with a contemporary housewife complaining about the foul oven-smell in her kitchen. Although both of these program elements, i.e. the serial Holocaust and the oven cleaner commercial were created by different people, independently, and for a different purpose, the programming brought them unexpectedly together, via Kuleshov effect.

Such contextual association is not restricted to television or audiovisual forms. Similar effects can, for example, be found in the printed media. Thus one can observe a photograph of an emaciated African woman with a dying child in her arms on one magazine page while on the opposing page, one can see a socialite claiming that she cannot survive without a new diamond. It is a parallel to Kuleshov's idea of two independent messages "A" and "B" creating a new message "C" if associated in some way. Implications of these mechanisms have been also addressed by the British art theoretician and critic John Berger, including his four-part, two-hour BBC TV serial Ways of Seeing. ${ }^{(17)}$

The Kuleshov effect is also an illustration of the power of context. This context is not limited to the autonomous structure of a work of art. Its impact does not have to come into full sight with such a dramatic eloquence like the examples described above. Yet it has to be taken into consideration. Unfortunately, many of these areas are still an uncharted territory, feeding on and contributing to film's and audiovisual media's many illusions. Viewers live these illusions -- often without realising that their impact on their own lives may become surprisingly real.

\section{Notes}

1. Max Wertheimer, Drei Abhandlungen zur Gestaltstheorie (Darmstadt: Wissenschaftliche Buchgesellschaft, 1967).

2. Let us leave aside the question of genuine the 3-D film, which involves two differing images delivered in front of the viewer through two discrete channels such as 3-D glasses, ribbed screen, or holographic techniques.

3. The importance of Welles' predecessors in this respect, such as Jean Renoir and Erich von Stroheim, is by no means to be underestimated.

4. Some filmmakers, however, sought an opposite effect, by reducing this illusion of depth, for example 


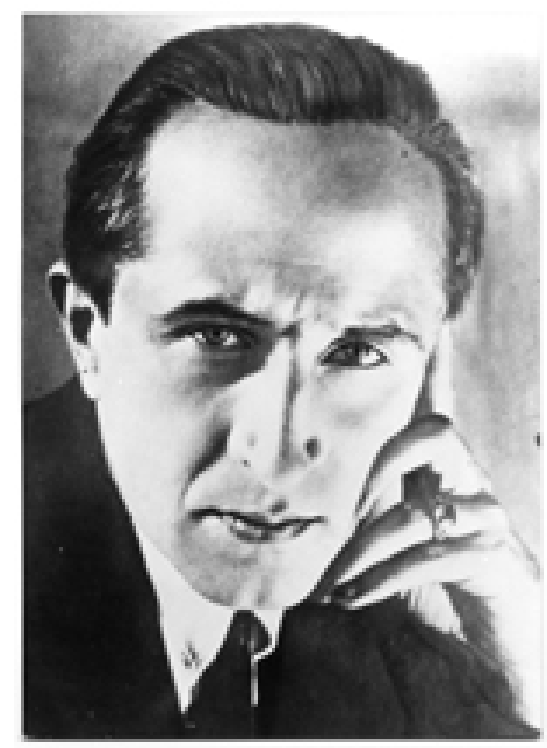

Figure 1: Lev Vladimirovich Kuleshov (1899-1970)

Jean-Luc Godard (La chinoise, Le Week-end). 5. Wiliam Hughes, "The Evaluation of Film as Evidence," The Historian and Film, Paul Smith ed. (Cambridge: Cambridge University Press, 1976), pp. 65-66. 6. Siegfried Kracauer, Nature of Film: The Redemption of Physical Reality (London: Dobbson, 1961), p. 158. In his book, Kracauer concluded that film should conform to its affinity by stressing the realistic aspect. A certain narrowness of this interpretation later provoked a critical reaction. 7. Hugo Mauerhofer, "Psychology of Film Experience," Penguin Film Review No. 8 (London, 1949).

8. Christian Metz, "The Imaginary Signifier," Film Theory and Criticism, Gerald Mast, Marshall Cohen, Leo Braudy ed. (Oxford: Oxford University Press, 1992), pp. 735-736.

9. Jean-Louis Baudry, "Ideological Effects of the Basic Cinematographic Apparatus," Film Theory and Criticism, Gerald Mast, Marshall Cohen, Leo Braudy ed. (Oxford: Oxford University Press, 1992), p. 311.

10. Walter Dadek, Das Filmmedium (Munich: Ernst Reinhardt, 1968), p. 133.

11. More on this topic in Nicholas Pronay, "The Newsreels: The Illusion of Actuality," The Historian and Film, Paul Smith ed. (Cambridge: Cambridge University Press, 1976), pp. 95-119.

12. Robert Lapsley and Michael Westlake, Film Theory: An Introduction (Manchester: Manchester University Press, 1988), pp. 182-183.

13. Other dialectical pairs include realism and expressivity, montage principle and the long take, and the centripetal and centrifugal (or off-screen) composition.

14. Marc Ferro, L'information en uniforme: Propagande, désinformation, censure, et manipulation (Paris: Editions Ramsay, 1991), p. 88.

15. "...radio had a peculiar ability to compress narrative time and space. The cinematic term montage isn't applicable because the joints were undetectable. The musical term segue is more appropriate: radio segments followed each other continually and easily without a break. ...this segue technique was an important model for TV, in which 'lead-ins' are an essential device." James Monaco, How To Read a Film, Oxford 1981, p. 376.

16. This aspect is valid only in the case of the commercial television; this is the one we are addressing here.

17. Also published as a book. 


\section{References}

\section{Literature}

Baudry, Jean-Louis. "Ideological Effects of the Basic Cinematographic Apparatus." Film Theory and Criticism, Gerald Mast, Marshall Cohen, Leo Braudy ed. Oxford: Oxford University Press, 1992.

Dadek, Walter. Das Filmmedium. Munich: Ernst Reinhardt, 1968.

Dondis, Donis A. A Primer of visual Literacy. Boston: MIT, 1973.

Ferro Marc. L'information en uniforme: Propagande, désinformation, censure, et manipulation. Paris: Editions Ramsay, 1991.

Kracauer, Siegfried. Nature of Film: The Redemption of Physical Reality. London: Dobbson, 1961.

Lapsley, Robert and Michael Westlake. Film Theory: An Introduction. Manchester: Manchester University Press, 1988.

Leyda, Jay. Kino: A History of the Russian and Soviet Film. London: Allen and Unwin, 1960.

Metz, Christian. "The Imaginary Signifier," Film Theory and Criticism, Gerald Mast, Marshall Cohen, Leo Braudy ed. (Oxford: Oxford University Press, 1992).

Monaco, James. How to Read a Film. New York: Oxford, 1981.

Sobchack, Thomas and Vivian Sobchack. An Introduction to Film. Boston: Little, Brown, 1987.

Sobchack, Vivian. The Address of the Eye: A Phenomenology of Film Experience. New Jersey: Princeton University Press, 1992.

Smith, Paul (ed). The Historian and Film. Cambridge: Cambridge University Press, 1976.

Wertheimer, Max. Drei Abhandlungen zur Gestaltstheorie. Darmstadt: Wissenschaftliche Buchgesellschaft, 1967.

\section{Author Information}

Jan UHDE is Professor Emer. (Film Studies) at the University of Waterloo, Ontario, Canada. Born in Brno, Czech Republic. Graduated (MA) from the Faculty of Arts, Masaryk University, Brno; PhD received at the University of Waterloo, Ontario, Canada. He taught at the University of Waterloo (1970-2012) where he founded a General and Honours BA program in Film Studies at the Department of Fine Arts.

Publications: Latent Images: Film in Singapore Second edition, with Yvonne Ng Uhde (Ridge Books, National University Press of Singapore, 2010); Latent Images: Film in Singapore, with Yvonne Ng Uhde (Oxford University Press, 2000); Latent Images: Film in Singapore CD-ROM (2003, co-author); Vision and Persistence: Twenty Years of the Ontario Film Institute (University of Waterloo Press, 1990) and Ontario Film Institute Programming Activities Index 1969-1989 (Toronto: Ontario Science Centre, 1990). He co-edited the Place in Space: Human Culture in Landscape (Proceedings from the Second International Conference of the Working Group "Culture and Landscape" of the International Association of Landscape Ecology, Pudoc Scientific Publishers, Wageningen, Holland, 1993). Jan Uhde has published articles and reviews in several countries (including Canada, USA, Germany, Italy), participated in international juries at film festivals and presented papers at international conferences in North America and Europe. In 1998/99, he was a visiting researcher at the School for Film and Media Studies, Ngee Ann Polytechnic, Singapore.

His professional and research interests focus on Singapore cinema; the identification and distancing mechanisms of the film viewer; the non-authored modifications and manipulation of films; and specific aspects of film history, including the Central European cinema.

He founded KINEMA in 1993. 